\title{
Donor site morbidity of the fasciocutaneous radial forearm flap: what does the patient really bother?
}

\author{
Christien A. de Witt $\cdot$ Remco de Bree . \\ Irma M. Verdonck-de Leeuw • Jasper J. Quak • \\ C. René Leemans
}

Received: 30 November 2006 / Accepted: 9 February 2007 / Published online: 24 February 2007

(C) Springer-Verlag 2007

\begin{abstract}
The objective of this study was the evaluation of donor site morbidity in head and neck cancer patients after reconstruction using a free vascularized radial forearm flap with emphasis on subjective complaints. Fifty patients who underwent at least 6 months before a reconstruction using a free vascularized radial forearm flap were asked to fill out two questionnaires regarding cosmetics and sensibility and forearm disabilities. Furthermore, a function test including movement extensions (flexion-extension, ulnar-radial deviation and pronation-supination), strength (pinch and grip) and temperature (digiti I and V) of the donor and non-donor site were measured and compared. Thirty-five percent of the patients reported no complaints regarding cosmetics and sensibility and $75 \%$ mentioned no forearm disabilities. There was no difference in movement extensions, temperature and grip strength between donor and non-donor sites. The difference in pinch strength appeared to be significant $(p<0.001)$. The total score of the questionnaire on forearm disabilities correlated significantly with extension, pronation and grip strength of the donor arm. Donor site morbidity of the radial forearm flap measured by objective functional tests was limited but subjective self-ratings revealed complaints regarding cosmestics and sensibility and to a lesser extent regard-
\end{abstract}

C. A. de Witt · R. de Bree $(\varangle) \cdot$ I. M. Verdonck-de Leeuw ·

J. J. Quak · C. R. Leemans

Department of Otolaryngology/Head and Neck Surgery,

VU University Medical Center,

De Boelelaan 1117, PO Box 7057,

1007 MB Amsterdam, The Netherlands

e-mail: r.bree@vumc.nl ing forearm disability. The present data may be used for solid patient counselling.

Keywords Free radial forearm flap .

Donor site morbidity · Head and neck cancer .

Functional results $\cdot$ Cosmetics

\section{Introduction}

The free radial forearm flap (FRFF), introduced by Yang et al. in 1981 [1], has established itself as a versatile, reliable and widely used method for reconstruction of defects in the head and neck region $[2,3]$. The pliability and thinness of FRFF allow its use in complex reconstructions. The vascular pedicle of the FRFF provides adequate vessel diameter and length for microvascular anastomosis. A split skin graft is most frequently used for the forearm donor site reconstruction. Donor site morbidity includes functional and aesthetical outcome. Hand and wrist function is the most important issue in the assessment of morbidity of the FRFF. In a previous study we found that donor site morbidity of the radial forearm flap measured by objective functional tests is negligible but in the patient's perception this is substantial [4]. Some retrospective studies describe a reduced forearm and/or wrist mobility and a reduced strength [5], stiffness of the wrist with movement disability, dysaesthesia, swelling of hand and/or wrist and pain [6], reduced sensibility of the radial nerve area and a less aesthetic result [7, 8], while others describe rare or no movement disabilities after using the FRFF $[9,10]$.

The subjective morbidity after harvest of the FRFF is one of the reasons that some reconstructive surgeons 
shift their attention to other fasciocutaneous flaps for reconstruction of defects in the head and neck $[11,12]$. The goal of the present study is to investigate these subjective complaints in more detail and in relation to the objective function tests in a larger group of patients.

\section{Methods}

\section{Patients}

All patients who visited the outpatient clinic of the department of otolaryngology/head and neck surgery of the VU Medical Center during the period of March till July 2004 and had a reconstruction of the surgical defect by using a FRFF at least 6 months before were asked to participate in the study. Exclusion criteria were arthritis of the upper extremities or a recent trauma of the wrist and/or lower arm.

During this period 69 patients, who underwent such a operation, visited the outpatient clinic. Fifty patients ( 28 men and 22 women, aged between 26 and 77 years, mean $59.2 \pm 11.1$ years) met the inclusion criteria. Eight of these 50 patients had had a forearm or wrist injury before surgery (five patients had a wrist fracture, two had a Dupyutren's contracture and one had surgery because of a ganglion on dorsal side of the wrist), of which four patients at the donor side. None of these patients had pre-existing complaints and/or range of motion disability of the hand or wrist. In 45 patients the left arm was used for the harvest of the FRFF and in five patients the right arm. In three patients the donor side was the side of the dominant hand.

Harvest of the flap was done simultaneously with the ablative procedure whenever possible. All patients underwent a preoperative and intra-operative Allen's occlusion test to rule out inadequate blood supply from the ulnar artery. Fasciocutaneous flaps were raised under a tourniquet in a conventional subfascial or superfascial manner about $2 \mathrm{~cm}$ proximal to the wrist skin fold. The superficial radial nerve and branches of the lateral antecubital nerve were preserved. The cephalic vein was used as donor vein. The radial artery was not reconstructed in any patient. The donor defect was closed with a split skin graft $(0.6 \mathrm{~mm})$ taken from the upper thigh at the same site. In order to aid healing the arm a pressure dressing of a paraffin gauze and foam was placed over the skin and the arm was immobilized for 7 days in a dorsal handto-upper-arm splint.
Donor site morbidity questionnaires

Subjectively the donor site morbidity was measured by means of a questionnaire regarding cosmetics and sensibility (Table 1) and a questionnaire regarding forearm disabilities of the operated arm (Table 2). Response possibilities were yes, no, or not applicable. All themes relate to the last $24 \mathrm{~h}$. A total score on each questionnaire was calculated by dividing all yes-scores by the number of questions answered yes or no. The total score ranged from 0 to 100 with 0 indicating no problems (no disability) and 100 indicating severe problems (severe forearm and/or wrist disabilities).

Table 1 Questionnaire regarding sensibility and cosmetics of the donor $\operatorname{arm}(n=50)$

\begin{tabular}{ll}
\hline Questions & $\begin{array}{l}\text { Number of } \\
\text { positive answer (\%) }\end{array}$ \\
\hline $\begin{array}{l}\text { No complaints } \\
\text { Complaints }\end{array}$ & $17(35)$ \\
$\begin{array}{l}\text { 1. Can you wear a wristwatch } \\
\text { or bracelet? }\end{array}$ & $12(24)$ \\
$\begin{array}{l}\text { 2. Does the hand feel numb? } \\
\text { 3. Does the scar itch? }\end{array}$ & $11(22)$ \\
$\begin{array}{l}\text { 4. Do you experience problems } \\
\text { in the cold? }\end{array}$ & $11(22)$ \\
5. Does the appearance bother you? & $13(27)$ \\
\hline
\end{tabular}

In case of complaints, multiple answers were possible

Table 2 Questionnaire regarding forearm disabilities in the last $24 \mathrm{~h}(n=50)$

Questions Number of positive answer (\%)

No forearm disabilities $38(75)$

Disabilities

1. I wake up at night because

of my forearm

2. I have complaints lying on

my forearm

3. I have complaints during daily

$2(4.0)$

life activities

4. I have complaints during movements

of my wrist

5. I have complaints during leaning on

my elbows or hands

6. I have complaints with

writing (or typing)

7. I have complaints holding my wheel

of my car or bike

8. I have complaints during lifting an object

$5(10.0)$

9. I have complaints opening or closing a door

10. I rub my wrist or forearm more

9 (18.0)

than once a day

11. I am irritable for people in my environment due to my forearm
$1(2.0)$ 
Donor site morbidity tests

Three tests were used for objective measurement of donor site morbidity. All measurements were performed at the operated and non-operated side. The first test covers movement extensions of the wrist. The angles of the maximal flexion and extension of the wrist, the ulnar and radial abduction and the lower arm pronation and supination were measured by the Mediclino Inclinometer (Bodybow-Holland, Nieuwegein, The Netherlands) with an accuracy of $2^{\circ}$ and a range of $0-180^{\circ}$ (Fig. 1).

The second test measures the strength of the hand. The grip strength (strength measured in the hand) was measured in $\mathrm{kg} / \mathrm{m}^{2}$ with a hydraulic dynamometer (Smith \& Nephew Roylan, Germantown, WI, USA) with an accuracy of $2.0 \mathrm{~kg}$ and a range of $0-90.0 \mathrm{~kg}$ (Fig. 2). The pinch-strength (strength of digiti I and V) was measured with a pinch gauge (B\&L Engineering, Santa Fe Springs, CA, USA) with an accuracy of $0.5 \mathrm{~kg}$ and a range of $0-12.5 \mathrm{~kg}$ (Fig. 3).

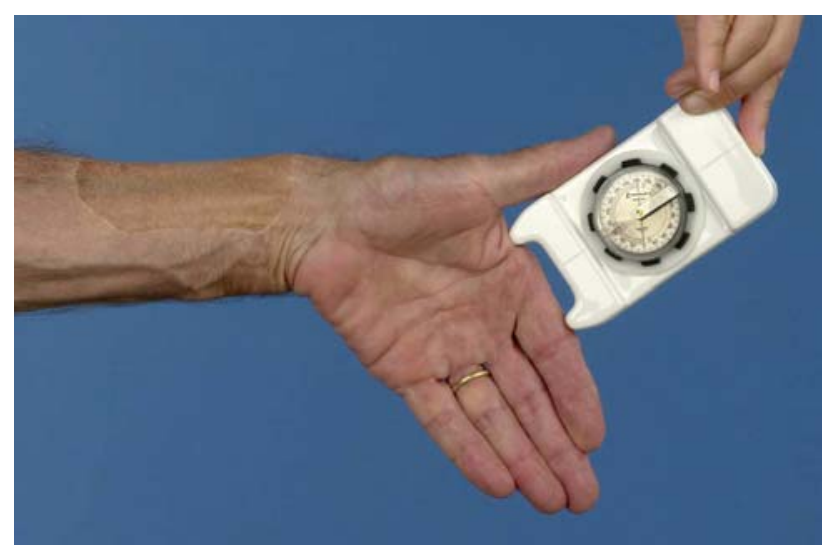

Fig. 1 Inclinometer used for measuring of movements

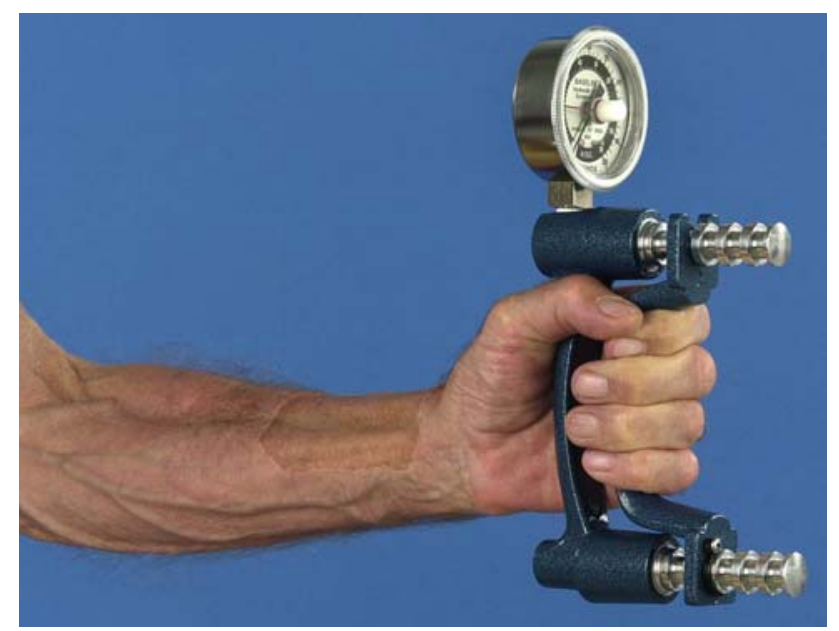

Fig. 2 Hydraulic dynamometer used for measuring grip strength
The third test measures the skin temperature of digiti I and V with a Tempcontrol MT $100 \mathrm{KC}$ and probe (Tempcontrol Industrial Electronic Products, Voorburg, The Netherlands) on the skin surface with an accuracy of $0.1^{\circ} \mathrm{C}$ and a range of -200 to $1350^{\circ} \mathrm{C}$.

\section{Statistical analyses}

Descriptive statistics were generated for the range of outcome variables in the study. Student's $t$-tests were used to determine the differences in objective tests between the donor and non-donor site. Spearman correlation-coefficients were calculated to assess correlations between subjective and objective forearm disability.

For all tests, a two-sided $p$-value less than .05 was considered statistically significant.

\section{Results}

Regarding subjective evaluation of cosmetics and sensibility, $35 \%$ of the patients had no complaints. The other patients scored positively (thus indicating complaints) on several of the questions (Table 1).

Regarding forearm disabilities, $75 \%$ of the patients had no complaints (Table 2). The other patients showed a variety of complaints, especially on rubbing and lifting an object. The mean total score on the forearm disability questionnaire was 4.6 (SD 12.6) with a range from 0 to 82 .

The results of the objective tests revealed that no differences were measured between the donor and non-donor arm regarding movement, grip and temperature. Pinch values appeared to be significantly different (Table 3).

The total score on the forearm disabilities questionnaire appeared to be significantly related to extension

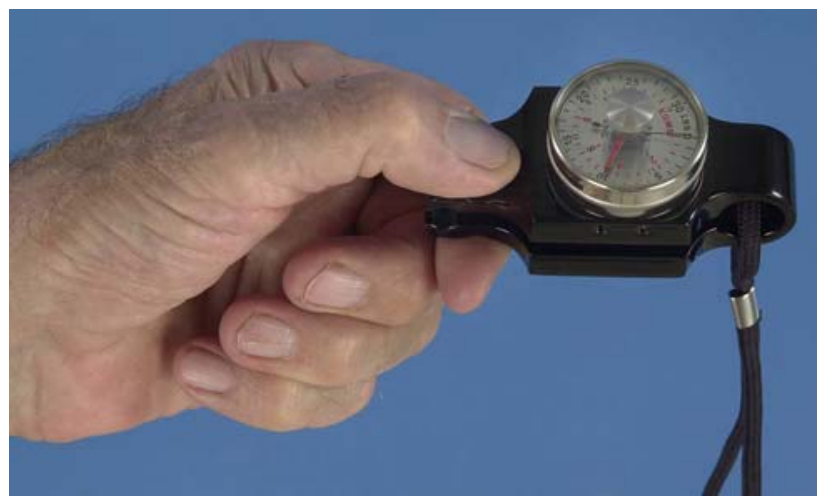

Fig. 3 Pinch gauge used for measuring pinch strength 
Table 3 Movement extensions, strength and temperature of donor and non-donor wrist and hand

\begin{tabular}{lrrrrr}
\hline & \multicolumn{2}{l}{ Donor side } & & \multicolumn{2}{c}{ Non-donor side } \\
\cline { 2 - 3 } \cline { 6 - 6 } & Mean & SD & & Mean & SD \\
\hline Extension & 57.3 & 11.7 & & 59.8 & 11.0 \\
Flexion & 71.1 & 8.0 & & 70.2 & 9.2 \\
Ulnar abduction & 57.7 & 8.2 & & 58.9 & 8.0 \\
Radial abduction & 15.3 & 8.4 & & 14.8 & 5.1 \\
Pronation & 85.4 & 10.8 & & 85.3 & 11.0 \\
Supination & 79.6 & 12.2 & & 80.4 & 12.9 \\
Grip & 28.7 & 10.4 & 29.9 & 9.7 \\
Pinch & 7.4 & 2.4 & 8.0 & $2.4 *$ \\
Temperature digit I & 29.3 & 3.3 & & 29.4 & 3.6 \\
Temperature digit V & 29.0 & 3.9 & 29.1 & 4.1 \\
\hline
\end{tabular}

*Significant difference $(p$-value $<.01))$

$(r=0.29, p<0.05)$, pronation $(r=0.30, p<.05)$ and grip strength $(r=0.30, p<.05)$.

\section{Discussion}

The most important goal of reconstructive surgery in head and neck cancer patients is the optimal restoration of function. The FRFF is a very reliable flap which can restore function in the head and neck function very well $[13,14,15]$. However, the donor site morbidity after harvesting the flap is another important issue. While the main postoperative concern was the reconstruction site, during follow-up the donor site become more important to patients [16].

Hand and wrist functions are important in the assessment of morbidity of the FRFF. The only objectively observed difference in our study was pinch strength between operated and non-operated sides. It must be emphasized that in $94 \%$ of the patients the FRFF was harvested from non-dominant side. Therefore, the pinch strength on the operated arm may be already less than on the non-operated side before surgery. All other functional tests revealed no statistically significant differences between operated and non-operated sides. Also Ho et al. [17] did not find any significant difference between the operated and the nonoperated arm for strength, range of motion and dexterity.

The questionnaires on the other hand revealed donor site complaints related to the FRFF. This difference between objective and subjective findings was also reported by others $[4,7,8,9]$. The questionnaire on forearm disabilities showed that the vast majority (75\%) of the patients had no functional complaints at all. The most frequent positive answer was about rubbing the forearm, which may be more a sensibility than a functional problem. In a study of Toschka et al. [18] postoperative hand function received a subjective rating of $80-100 \%$ of the preoperative function by $89 \%$ of their patients. Other studies report no subjective impairment of function in $63-100 \%$ of patients $[7,10]$. Ho et al [17] found using a questionnaire consisting of a list of activities of daily living (ADL) that required use of wrist and forearm, that postoperative function appears to be quite satisfactory.

While the forearm disability questionnaire showed that functional problems are limited, the cosmetics and sensibility questionnaire revealed that only $39 \%$ of the patients had no cosmetic or sensible complaints. The most frequent $(27 \%)$ complaint was on the appearance of the donor site. Other studies found complaints of poor aesthetic results in up to $28 \%$ of patients, particularly female patients $[7,9,10,16]$. Bardsley et al. [10] examined the cosmetic result by a subjective assessment on a scale of $0-10$. The cosmetic result was acceptable in men (mean score 1.5) but was less so in women (mean score 4). Ito et al. [16] scored the dissatisfaction about the FRFF donor site of 23 patients in five items: color (4\%), scar width $(0 \%)$, depression $(30 \%)$, wrist mobility $(0 \%)$ and sensation $(4 \%)$. The majority of patients $(61 \%)$ had no complaints at all. The mean number of items of which patients were dissatisfied was 0.39 . On the other hand in the study of Toschka et al. [18] 94\% of the patients rated the aesthetic outcome as fair or good. Lutz et al. [8] reported $98 \%$ of patients rating the aesthetic outcome as satisfactory.

Only extension, pronation and grip strength had a clear correlation with the score on the forearm disabilities questionnaire. For all other objective test no significant correlation with this score was found. Therefore, most objective test results may not be indicative for donor site complaints by the patient. This finding has been confirmed earlier by others $[4,7,8,9]$.

To diminish donor site morbidity several harvesting and donor site closure technique modifications have been proposed.

The technique of harvesting the flap may have some impact on donor site function. In the early days of this flap when radial bone was included for mandibular reconstruction, morbidity was substantial, even leading to wrist fractures [7]. Suprafascial dissection is claimed by some to lead to superior results from a standpoint of wound healing, but there are no comparative studies that confirm this $[8,18]$. Wolff et al. [19] reported on a small series of prefabricated fascial-split-thickness skin flap: after a split-thickness skin graft is transplanted to the forearm fascia the flap can be raised with complete preservation of the forearm skin and microsurgically 
transplanted like a conventional radial flap. The prelaminated fasciomucosal radial forearm flap as described by Nehrer-Tairych et al. [20] claims to provide better cosmetic and functional donor site effects, although the series of patients they describe is rather small.

Avery et al. [5] reported good aesthetic results of repair of the FRFF donor site by full-thickness skin graft from the inner upper arm. Ho et al. [17] compared the functional and aesthetic outcomes of FRFF donor sites reconstructed with full-thickness skin graft, split skin graft alone and split skin graft overlying an acellular dermal matrix and found that all three methods of reconstruction have comparable low morbidity, postoperative satisfactory aesthetic and functional outcomes. Negative pressure wound dressing has been used for rapid healing and decreased donor site complications [21]. Bardsley et al. [10] used a ulnar artery-based transposition flap for primary closure to reduce wound healing and improve cosmetic results. Hsieh et al. [22] reported good results of primary closure of the FRFF donor site with a bilobed flap based on the fasciocutaneous perforator of the ulnar artery. Several types of tissue expansion have been reported to allow the use of local tissues for primary closure [23]. The preferred technique of closure is difficult to assess, because of limited comparative studies, limited number of patients and lack of significant differences.

The presented data can be used for solid counselling patients who are scheduled for FRFF reconstruction. Elaborate pre-surgical counselling may reduce the impact of functional and cosmetic impairment at the FRFF donor site [24]. Moreover, these data may serve as benchmark for future studies that use other free fasciocutaneous flaps.

\section{Conclusion}

Donor site morbidity of the radial forearm flap measured by objective functional tests is negligible but in the patient's perception this is substantial. Subjective measurements show especially problems in cosmesis and sensibility. The present data may be used for solid patient counselling.

\section{References}

1. Yang G, Chen B, Gao Y (1981) Forearm free skin flap transplantation. Natl Med J China 61:139

2. Soutar DS, Scheker LR, Tanner NS, McGregor IA (1983) The radial forearm flap: a versatile method for intra-oral reconstruction. Br J Plast Surg 36:1-8
3. Evans FGR, Schusterman MA, Kroll SS, Miller MJ, Reece GP, Robb GL, Ainslie N (1994) The radial forearm free flap for head and neck reconstruction: a review. Am J Surg 168:446-450

4. Bree R de, Hartley C, Smeele LE, Kuik DJ, Quak JJ, Leemans CR (2004) Evaluation of donor site function and morbidity of the fasciocutaneous radial forearm flap. Laryngoscope 114:1973-1976

5. Avery CME, Iqbal M, Hayter JP (2005) Repair of radial free flap donor site by full-thickness skin graft from inner arm. $\mathrm{Br}$ J Oral Maxillofac Surg 43:161-165

6. Brown MT, Couch M E, Huchton DM (1999) Assessment of donor-site functional morbidity from radial forearm fasciocutaneous free flap harvest. Arch Otolaryngol Head Neck Surg 125:1371-1374

7. Richardson D, Fisher SE, Vaughan ED, Brown JS (1997) Radial forearm flap donor-site complications and morbidity: a prospective study. Plast Reconstr Surg 99:109-115

8. Lutz BS, Wei FC, Chang SC, Yang KH, Chen IH (1999) Donor site morbidity after suprafascial elevation of the radial forearm flap: a prospective study in 95 consecutive cases. Plast Reconstr Surg 103:132-137

9. Swanson E, Boyd JB, Manktelow RT (1990) The radial forearm flap: reconstructive applications and donor-site defects in 35 consecutive patients. Plast Reconstr Surg 85:258-266

10. Bardsley AF, Soutar DS, Elliot D, Batchelor AG (1990) Reducing morbidity in the radial forearm flap donor site. Plast Recontsr Surg 86:287-292

11. Huang C-H, Chen H-C, Huang Y-L, Mardini S, Feng G-M (2004) Comparison of the radial forearm flap and the thinned anterolateral thigh cutaneous flap for reconstruction of tongue defects: an evaluation of donor-site morbidity. Plast Reconstr Surg 114:1704-1710

12. Gellrich NC, Kwon TG, Lauer G, Fakler O, Gutwald R, Otten JE, Schmelzeisen R (2000) The lateral upper arm free flap for intraoral reconstruction. Int $\mathrm{J}$ Oral Maxillofac Surg 29:104-111

13. Borggreven PA, Verdonck-de Leeuw I, Langendijk JA, Doornaert P, Koster MN, Bree R de, Leemans CR (2005) Speech outcome after surgical treatment for oral and oropharyngeal cancer: A longitudinal assessment of patients reconstructed by a microvascular flap. Head Neck 27:785-793

14. Su WF, Hsia YJ, Chang YC, Chen SG, Sheng H (2003) Functional comparison after reconstruction with a radial forearm free flap or a pectoralis major flap for cancer of the tongue. Arch Otolaryngol Head Neck Surg 128:412-418

15. Hara I, Gellrich NC, Duker J, Schon R, Fakler O, Smelzeisen R, Honda T, Satoru O (2003) Swallowing and speech function after intraoral soft tissue reconstruction with lateral upper arm free flap and radial forearm free flap. Br J Oral Maxillofacial Surg 41:161-169

16. Ito O, Igawa HH, Suzuki S, Muneuchi G, Kawazoe T, Saso Y, Onodera M, Park S, Hata Y (2005) Evaluation of the donor site in patients who underwent reconstruction with a free radial forearm flap. J Reconstr Microsurg 21:113-117

17. Ho T, Couch M, Carson K, Schimberg A, Manley K, Byrne PJ (2006) Radial forearm free flap donor site outcomes comparison by closure methods. Otolaryngol Head Neck Surg 134:309-315

18. Toschka H, Feifel H, Erli HJ, Minkenberg R, Paar O, Riediger D (2001) Aesthetic and functional results of harvesting radial forearm flap, especially with regard to hand function. Int J Oral Maxillofac Surg 30:42-48

19. Wolff KD, Ervens J, Hoffmeister B (1996) Improvement of the radial forearm donor site by prefabrication of fascialsplit-thickness skin grafts. Plast Reconstr Surg 98:358-362 
20. Nehrer-Tairych GV, Millesi W, Schuhfried O, Rath T (2002) A comparison of the donor-site morbidity after using the prelaminated fasciomucosal flap and the fasciocutaneous radial forearm flap for intraoral reconstruction. Br J Plast Surg 55:198-202

21. Avery C, Pereira J, Moody A, Garguilo M, Whitworth (2000) Negative pressure wound dressing of the radial forearm donor site. Int J Oral Maxillofac Surg 29:198-200

22. Hsieh C-H, Kuo Y-R, Yao S-F, Liang C-C, Jeng S-F (2004) Primary closure of radial forearm flap donor defects with a bi- lobed flap based on the fasciocutaneous perforator of the ulnar artery. Plast Reconstr Surg 113:1355-1360

23. Berge SJ, Wiese KG, Lindern JJ von, Niederhagen B, Appel T, Reich RH (2001) Tissue expansion using osmotically active hydrogel systems for direct closure of the donor defect of the radial forearm flap. Plast Reconstr Surg 108:1-5

24. Suominen S, Ahovuo J, Asko-Seljavaara S (1996) Donor site morbidity of radial forearm flaps. A clinical and ultrasonographic evaluation. Scand J Plast Reconstr Surg Hand Surg 30:57-61 